\title{
Land-price dynamics and macroeconomic fluctuations with nonseparable preferences
}

\author{
Liutang Gonga, Chan Wang ${ }^{\mathrm{b}, *}$, Fuyang Zhao ${ }^{\mathrm{a}}$, Heng-fu Zou ${ }^{\mathrm{c}}$ \\ a Guanghua School of Management and LMEQF, Peking University, Beijing 100871, China \\ ${ }^{\mathrm{b}}$ School of Finance, Central University of Finance and Economics, Beijing 100081, China \\ ${ }^{\mathrm{c} C h i n a}$ Economics and Management Academy, Central University of Finance and Economics, Beijing 100081, China
}

\section{A R T I C L E I N F O}

\section{Article history:}

Received 22 December 2016

Revised 27 May 2017

Accepted 25 July 2017

Available online 18 August 2017

\section{JEL classification:}

E5

F3

F4

Keywords:

Collateral constraint

Housing demand shock

Nonseparable preferences

Macroeconomic fluctuations

\begin{abstract}
A B S T R A C T
In this paper, we introduce a complementary relationship between consumption and labor hours by revising the household's period utility function in Liu et al. (2013). The revision concomitantly allows for a finite Frisch elasticity of labor supply and a stronger consumption smoothing motive. We find that, in general, the estimation of Liu et al. (2013) is quite robust. In addition, the propagation mechanism of the credit constraint triggered by a housing demand shock still persists. However, the amplification effect of the credit constraint triggered by the housing demand shock on key macroeconomic variables is greatly muted. We also find that, except for land price fluctuations, the housing demand shock cannot act as the primary force to drive the fluctuations in other macroeconomic variables.
\end{abstract}

(c) 2017 Published by Elsevier B.V.

\section{Introduction}

The Great Recession has turned academic researchers' interest to financial frictions. Since the seminal work of Kiyotaki and Moore (1997), many academic researchers find that the borrowing constraints can powerfully propagate and amplify a small shock by changing the net worth of credit-constrained agents. ${ }^{1}$ The experience of the U.S. housing market during the period of the Great Recession has led many academic researchers to believe that house prices could be one of the key driving forces of business cycles. Recently, Liu et al. (2013) introduce land as a collateral asset in firms' credit constraints and find that a housing demand shock can trigger a mechanism that propagates and amplifies the shock through the joint dynamics of land prices and business investment. Their estimation also shows that a housing demand shock alone can account for about $90 \%$ of land-price fluctuations, 30-40\% of investment fluctuations, 20-30\% of output fluctuations, and $35-45 \%$ of labor hours fluctuations.

However, Liu et al. (2013)'s striking conclusions are based on some assumptions about the representative household's period utility function. Following Hansen (1985) and Rogerson (1988), Liu et al. (2013) assume that the period utility function is linear in leisure, thus it implies that Frisch elasticity of labor supply is infinite. But the recent research on the topic

\footnotetext{
* Corresponding author.

E-mail addresses: wangchanist@gmail.com, wangchanist@126.com (C. Wang).

1 See, among many others, Iacoviello (2005), Iacoviello and Neri (2010), Jermann and Quadrini (2012), Favilukis et al. (2017), Liu et al. (2016); 2013).
} 
has rejected the assumption. ${ }^{2}$ Liu et al. (2013) also assume that the period utility function is separable in consumption and labor. By comparison, since Becker (1965), Kydland and Prescott (1982), and Greenwood et al. (1988), many economists emphasize that consumption and labor being complements has important implications for business cycles. Do Liu et al. (2013)'s striking conclusions hold if we generalize the household's period utility function to allow for a complementary relationship between consumption and labor hours and a finite Frisch elasticity of labor supply?

In this paper, following Kydland and Prescott (1982), Backus et al. (1992), Chari et al. (1994, 2000) and Schmitt-Grohe and Uribe (2007), we assume a complementary relationship between consumption and labor hours in household's period utility function of Liu et al. (2013). Our revision of the household's period utility function has two accompanying advantages. First, in our model, Frisch elasticity of labor supply is finite intrinsically. Second, the household prefers consumption smoothing while, in Liu et al. (2013), the period utility function is logarithmic in consumption, which implies that when the interest rate changes, the income effect equals the substitution effect and saving is not affected by the changes in the interest rate.

Following Liu et al. (2013), we fit the log-linearized equilibrium system to the same data and use the Bayesian method to estimate the revised model. In general, the estimated parameters of our model with a complementary relationship between consumption and labor hours suggest that the estimation of Liu et al. (2013) is quite robust. In addition, we find that the propagation mechanism through the collateral channel triggered by a housing demand shock still persists. However, the amplification effect on key macroeconomic variables is greatly reduced, due to the combined effects of a complementary relationship between consumption and labor hours, a finite Frisch elasticity of labor supply, and the household's consumption smoothing motive.

When the household prefers consumption smoothing, after a housing demand occurs, the household is less willing to decrease the consumption and lend to the credit-constrained entrepreneur. Thus, after a positive housing demand shock occurs, the land price increases following the household's higher demand for land, which expands the entrepreneur's net worth and thus loosens her borrowing constraint. However, the household's unwillingness to lend than before reduces the amount of credit that the entrepreneur can borrow. As a result, the entrepreneur's land demand curve does not move as high as that in Liu et al. (2013). Thus, the demand for land from the entrepreneur is depressed. It means that the competing demand for land cannot drive the land price up to the same level as in Liu et al. (2013). Accordingly, the static financial multiplier is not as large as that in Liu et al. (2013).

In spite of the fact that the entrepreneur's borrowing capacity is weaken by the household's unwillingness to lend, the rise in the land price still expands her net worth and causes her to borrow from the household, thus the household's consumption falls. In the presence of a complementary relationship between consumption and labor, the fall in household's consumption induces the household to supply less labor and enjoy more leisure. In addition, a smaller Frisch elasticity of labor supply than that in Liu et al. (2013) also contributes the relative reduction in household's labor supply.

The lower labor supply in our model has important implications for the entrepreneur's investment and land price. The previous analysis implies that the business investment at the time when the housing demand shock hits the economy is lower than that in Liu et al. (2013), thus the capital stock in the future is also lower in our model. In addition, since the capital and labor hours are complementary in the production function, the relative reduction in labor supply decreases the marginal product of the capital, which lowers the shadow price of capital in consumption units. Thus, the entrepreneur's willingness to invest is lower than that in Liu et al. (2013), which further reduces the future capital stock. The relative decline in the capital stock and the shadow price of capital in consumption units reduces the value of the entrepreneur's collateral capital, and entrepreneur can borrow less from the household than that in Liu et al. (2013). In addition, there is a complementary relationship among three production factors, with the future capital stock and the labor hours being lower in our model, the future marginal product of land will also be lower, which reduces the current land price. Thus, the value of the entrepreneur's collateral land is lower than that in Liu et al. (2013). Our analysis implies that the degree to which the entrepreneur's credit constraint is relaxed is lower and a smaller dynamic financial multiplier emerges.

The above reasoning implies that, after a positive housing demand shock occurs, the major macroeconomic variables, including land price, investment, output, and labor hours, all respond upward, but weaker than before. Therefore, the amplification effect triggered by a housing demand shock through the credit constraint mechanism is far smaller than that claimed by Liu et al. (2013).

Furthermore, variance decompositions show that, except for the land price, a housing demand shock cannot act as the primary force to drive the fluctuations in other main macroeconomic variables. Specifically, the housing demand shock, as in Liu et al. (2013), can account for about $80 \%$ of land-price fluctuations. By comparison, a labor supply shock is the primary force to drive the fluctuations in output (about 40-60\%) and labor hours (about 60-80\%). As for investment, a patience shock accounts for most of fluctuations (about $40 \%$ ).

Our paper is related to the literature on questioning the quantitative significance of the amplification through the borrowing constraint channel. Kocherlakota (2000) demonstrates, in a small open economy with credit constraints, that the effect of the amplification through the borrowing constraint channel is sensitive to the structural parameters of the economy, especially to the shares of capital and land in the production function. Unlike Kocherlakota (2000), Cordoba and Ripoll (2004) directly modify Kiyotaki and Moore (1997) to introduce standard specifications of preferences and technologies. Specifically, two types of agents both have concave preferences and concave production technologies. They find that the output ampli-

\footnotetext{
2 See Chetty et al. (2012).
} 
fication due to the collateral constraints following a total factor productivity shock is small. In the literature, the models with the borrowing constraints in the spirit of Kiyotaki and Moore (1997) all assume that the markets are incomplete. Cao and Nie (2017) use a simplified version of Iacoviello (2005) to assess the relative importance of the borrowing constraints versus market incompleteness to propagate and amplify the shocks. They find that the market incompleteness by itself is responsible for amplifying the shocks. If the markets are complete, even the borrowing constraints are present, the amplification effect disappears. Dmitriev and Hoddenbagh (2017) revise Bernanke et al. (1999) to introduce forward-looking risk-averse entrepreneurs and derive the optimal state-dependent loan contract for them and find that, under the optimal state-dependent contract, the financial frictions deliver less amplification effect. As a comparison, our paper aims to question the amplification effect of a housing demand shock through the borrowing constraint channel in housing market and the primary role played by a housing demand shock in driving the fluctuations in the major macroeconomic variables, both of which are confirmed by Liu et al. (2013).

The rest of the paper is organized as follows. Section 2 lays out the model. Section 3 introduces the estimation strategy. Section 4 discusses the economic implications of nonseparability between consumption and leisure for the amplification effect of a housing demand shock through the borrowing constraint channel. Section 5 concludes.

\section{The model}

The model's structure is identical to Liu et al. (2013), the economy is populated by a representative household (patient) and a representative entrepreneur (impatient). The entrepreneur borrows from the household to finance her investment spending. The entrepreneur's borrowing capacity is constrained by the value of collateral assets which consist of the land and capital stock held by the entrepreneur. The entrepreneur inputs capital, labor and land to produce the consumption goods which are consumed by the household and the entrepreneur herself. The household consumes both consumption goods and housing services (by owning the land) and offers labor to the entrepreneur.

\subsection{The representative household}

Following Kydland and Prescott (1982), Backus et al. (1992), Chari et al. (1994); 2000) and Schmitt-Grohe and Uribe (2007), we assume that the household has the following utility function

$$
\mathbf{E}_{0} \sum_{t=0}^{\infty} \beta^{t} A_{t}\left\{\frac{\left(\left(1-N_{h t}\right)^{\psi_{t}}\left(C_{h t}-\gamma_{h} C_{h t-1}\right) / \Gamma_{t}\right)^{1-\sigma}}{1-\sigma}+\varphi_{t} \log L_{h t}\right\},
$$

in which $C_{h t}$ denotes consumption, $N_{h t}$ denotes labor hours, and $L_{h t}$ denotes land holdings. The parameter $\beta \in(0,1)$ denotes the subjective discount factor, $\sigma$ denotes the coefficient of relative risk aversion, and $\gamma_{h}$ measures the degree of habit persistence. Following Liu et al. (2016), we scale consumption by the growth factor $\Gamma_{t} \equiv\left[Z_{t} Q_{t}^{(1-\phi) \alpha}\right]^{\frac{1}{1-(1-\phi) \alpha}}$ to obtain balanced growth. ${ }^{3}$ The variables $A_{t}, \psi_{t}, \varphi_{t}$ represent the shock to the household's patient factor, the shock to labor supply, and the shock to housing demand respectively. Each of the shocks $A_{t}, \psi_{t}, \varphi_{t}$ follows the same stochastic process as that in Liu et al. (2013).

In the literature on business cycles and asset pricing, empirical estimates find that $\sigma$ is almost always above unity. ${ }^{4}$ When $\sigma$ is greater than unity, the marginal utility of household consumption is decreasing in leisure. In this sense, consumption goods and leisure are substitutes. Equivalently, there is a complementary relationship between consumption goods and labor hours. As will be evident, the minor revision of the household's period utility function in Liu et al. (2013) generates different macroeconomic fluctuations.

The household chooses consumption, land holdings, saving, and employment to maximize the utility function (1) subject to the following budget constraint

$$
C_{h t}+q_{l t}\left(L_{h t}-L_{h, t-1}\right)+\frac{S_{t}}{R_{t}} \leq w_{t} N_{h t}+S_{t-1}
$$

where $q_{l t}$ denotes the land price, $S_{t}$ denotes the risk-free bond, $R_{t}$ denotes the gross real loan rate, and $w_{t}$ denotes the real wage rate. In the initial period, the household is endowed with $L_{h,-1}>0$ units of land and $S_{-1}>0$ units of the risk-free bond. In addition, the household cannot borrow arbitrarily, it implies that she faces the borrowing constraint $S_{t} \geq-\bar{S}$ for a large number $\bar{S}$.

\footnotetext{
${ }^{3}$ In the following, we will see that $Z_{t}$ is the technology shock, and $Q_{t}$ is the investment-specific technological change.

4 See footnote 10 in Devereux et al. (2007).
} 


\subsection{The representative entrepreneur}

The representative entrepreneur's utility function is given by

$$
\mathbf{E}_{0} \sum_{t=0}^{\infty} \beta^{t}\left\{\log \left(C_{e t}-\gamma_{e} C_{e t-1}\right)\right\},
$$

where $C_{e t}$ denotes the consumption, and $\gamma_{e}$ measures the degree of habit persistence.

The entrepreneur uses a Cobb-Douglas technology to produce the consumption goods. Specifically, she produces the consumption goods according to

$$
Y_{t}=Z_{t}\left[L_{e, t-1}^{\phi} K_{t-1}^{1-\phi}\right]^{\alpha} N_{e t}^{1-\alpha}
$$

where $Y_{t}$ is the output, $L_{e, t-1}$ is land input, $K_{t-1}$ is capital input, and $N_{e t}$ is the labor input, the parameters $\alpha \in[0,1]$ and $\phi \in[0,1]$ are the output elasticities of input factors, and $Z_{t}$ is a technology shock which follows the same stochastic process as that in Liu et al. (2013).

The entrepreneur is initially endowed with $K_{-1}$ units of capital and $L_{e,-1}$ units of land. The entrepreneur faces the following flow-of-funds constraint

$$
C_{e t}+q_{l t}\left(L_{e t}-L_{e, t-1}\right)+B_{t-1}=Z_{t}\left[L_{e, t-1}^{\phi} K_{t-1}^{1-\phi}\right]^{\alpha} N_{e t}^{1-\alpha}-\frac{I_{t}}{Q_{t}}-w_{t} N_{e t}+\frac{B_{t}}{R_{t}},
$$

where $B_{t-1}$ is the matured debt level, $I_{t}$ is investment, and $Q_{t}$ is the investment-specific technological change which follows the same stochastic process as that in Liu et al. (2013).

The entrepreneur uses an investment technology to transform consumption goods to capital input. The law of motion of capital stock is

$$
K_{t}=(1-\delta) K_{t-1}+\left[1-\frac{\Omega}{2}\left(\frac{I_{t}}{I_{t-1}}-\bar{\lambda}_{I}\right)^{2}\right] I_{t},
$$

in which $\delta \in(0,1)$ is the depreciation rate of capital, $\Omega>0$ is the adjustment cost parameter, and $\bar{\lambda}_{I}$ is the steady-state growth rate of investment.

The costly contract enforcement problem facing the creditor emphasized in Kiyotaki and Moore (1997) implies that the entrepreneur's borrowing capacity is constrained by a fraction of the value of collateral assets. Specifically, the entrepreneur faces the following credit constraint

$$
B_{t} \leq \theta_{t} \mathbf{E}_{t}\left[q_{l, t+1} L_{e t}+q_{k, t+1} K_{t}\right]
$$

where $q_{k, t+1}$ is the shadow price of capital, $\theta_{t}$ is the fraction of the value of collateral assets. Eq. (7) implies that, when entrepreneur fails to repay the debt, the creditor can seize the collateral, the land and the accumulated capital. Since the liquidation of the collateral is costly, the creditor can only recoup up to $\theta_{t}$ units of the total value of collateral assets. Thus, $\theta_{t}$ denotes a collateral shock which follows the same stochastic process as that in Liu et al. (2013).

\subsection{Equilibrium}

There are four markets in the model. The markets for consumption goods, labor, land, and loanable bonds all clear in the equilibrium. The consumption goods market clearing condition is

$$
C_{t}+\frac{I_{t}}{Q_{t}}=Y_{t}
$$

where $C_{t}=C_{h t}+C_{e t}$ is aggregate consumption.

The labor market clearing condition is

$$
N_{e t}=N_{h t}=N_{t} \text {. }
$$

The land market clearing condition is

$$
L_{h t}+L_{e t}=\bar{L} \text {. }
$$

The bond market clearing condition is

$$
S_{t}=B_{t}
$$

A competitive equilibrium consists of a sequence of prices $\left\{w_{t}, q_{l t}, R_{t}\right\}_{t=0}^{\infty}$ and a sequence of allocations $\left\{C_{h t}, C_{e t}, I_{t}, N_{h t}, N_{e t}, L_{h t}, L_{e t}, S_{t}, B_{t}, K_{t}, Y_{t}\right\}_{t=0}^{\infty}$ such that (i) taking all prices as given, household's allocations maximize her utility,

(ii) taking all prices as given, entrepreneur's allocations maximize her utility, and (iii) all markets clear. 
Table 1

Prior distributions and posterior modes of structural parameters.

\begin{tabular}{|c|c|c|c|c|c|c|}
\hline \multirow[t]{2}{*}{ Parameter } & \multicolumn{3}{|l|}{ Prior } & \multicolumn{3}{|c|}{ Posterior mode } \\
\hline & Distribution & $\mathrm{a}$ & $\mathrm{b}$ & LWZ & $\sigma=1$ & $\sigma=2$ \\
\hline$\gamma_{h}$ & $\operatorname{Beta}(a, b)$ & 1.00 & 2.00 & 0.4976 & 0.5225 & 0.3564 \\
\hline$\gamma_{e}$ & $\operatorname{Beta}(a, b)$ & 1.00 & 2.00 & 0.6584 & 0.6347 & 0.8137 \\
\hline$\Omega$ & Gamma(a,b) & 1.00 & 0.50 & 0.1753 & 0.1301 & 0.0558 \\
\hline $100\left(g_{\gamma}-1\right)$ & $\operatorname{Gamma}(a, b)$ & 1.86 & 3.01 & 0.4221 & 0.3776 & 0.3405 \\
\hline $100\left(\bar{\lambda}_{q}-1\right)$ & Gamma(a,b) & 1.86 & 3.01 & 1.2126 & 1.2461 & 1.2443 \\
\hline$\beta$ & Simulated & & & 0.9855 & 0.9868 & 0.9879 \\
\hline $\bar{\lambda}_{a}$ & Simulated & & & 0.0089 & 0.0071 & 0.0057 \\
\hline $\bar{\varphi}$ & Simulated & & & 0.0457 & 0.0491 & 0.5507 \\
\hline$\phi$ & Simulated & & & 0.0695 & 0.0695 & 0.0696 \\
\hline$\delta$ & Simulated & & & 0.0368 & 0.0369 & 0.0373 \\
\hline
\end{tabular}

Table 2

Prior and posterior distributions of shock parameters.

\begin{tabular}{|c|c|c|c|c|c|c|}
\hline \multirow[t]{2}{*}{ Parameter } & \multicolumn{3}{|l|}{ Prior } & \multicolumn{3}{|c|}{ Posterior mode } \\
\hline & Distribution & $\mathrm{a}$ & $\mathrm{b}$ & LWZ & $\sigma=1$ & $\sigma=2$ \\
\hline$\rho_{a}$ & $\operatorname{Beta}(a, b)$ & 1.00 & 2.00 & 0.9055 & 0.9397 & 0.9382 \\
\hline$\rho_{z}$ & $\operatorname{Beta}(a, b)$ & 1.00 & 2.00 & 0.4263 & 0.0001 & 0.0008 \\
\hline$\rho_{v z}$ & Beta(a,b) & 1.00 & 2.00 & 0.0095 & 0.0414 & 0.0034 \\
\hline$\rho_{q}$ & $\operatorname{Beta}(a, b)$ & 1.00 & 2.00 & 0.5620 & 0.5609 & 0.6552 \\
\hline$\rho_{v q}$ & $\operatorname{Beta}(a, b)$ & 1.00 & 2.00 & 0.2949 & 0.3813 & 0.2204 \\
\hline$\rho_{\varphi}$ & $\operatorname{Beta}(a, b)$ & 1.00 & 2.00 & 0.9997 & 0.9996 & 0.9994 \\
\hline$\rho_{\psi}$ & $\operatorname{Beta}(a, b)$ & 1.00 & 2.00 & 0.9829 & 0.9961 & 0.9789 \\
\hline$\rho_{\theta}$ & $\operatorname{Beta}(a, b)$ & 1.00 & 2.00 & 0.9804 & 0.9843 & 0.9917 \\
\hline$\sigma_{a}$ & $\operatorname{Inv}-\operatorname{Gam}(\mathrm{a}, \mathrm{b})$ & 0.3261 & $1.45 \mathrm{e}-04$ & 0.1013 & 0.0847 & 0.2547 \\
\hline$\sigma_{z}$ & $\operatorname{Inv}-\operatorname{Gam}(\mathrm{a}, \mathrm{b})$ & 0.3261 & $1.45 e-04$ & 0.0042 & 0.0069 & 0.0068 \\
\hline$\sigma_{v z}$ & $\operatorname{Inv}-\operatorname{Gam}(a, b)$ & 0.3261 & $1.45 e-04$ & 0.0037 & 0.0015 & 0.0022 \\
\hline$\sigma_{q}$ & $\operatorname{Inv}-\operatorname{Gam}(\mathrm{a}, \mathrm{b})$ & 0.3261 & $1.45 \mathrm{e}-04$ & 0.0042 & 0.0040 & 0.0041 \\
\hline$\sigma_{v q}$ & $\operatorname{Inv}-\operatorname{Gam}(\mathrm{a}, \mathrm{b})$ & 0.3261 & $1.45 \mathrm{e}-04$ & 0.0029 & 0.0043 & 0.0041 \\
\hline$\sigma_{\varphi}$ & $\operatorname{Inv}-\operatorname{Gam}(\mathrm{a}, \mathrm{b})$ & 0.3261 & $1.45 \mathrm{e}-04$ & 0.0462 & 0.0466 & 0.0533 \\
\hline$\sigma_{\psi}$ & $\operatorname{Inv}-\operatorname{Gam}(a, b)$ & 0.3261 & $1.45 \mathrm{e}-04$ & 0.0073 & 0.0097 & 0.0095 \\
\hline$\sigma_{\theta}$ & $\operatorname{Inv}-\operatorname{Gam}(\mathrm{a}, \mathrm{b})$ & 0.3261 & $1.45 e-04$ & 0.0112 & 0.0122 & 0.0119 \\
\hline
\end{tabular}

\section{Estimation}

After log-linearizing the equilibrium system around the steady state in which the credit constraint is binding, we fit the log-linearized equilibrium system to the same data used by Liu et al. (2013). We also use the Bayesian method to estimate the model, and our estimation strategy is identical to that used by Liu et al. (2013). ${ }^{5}$ First, we use the steady-state values and ratios to calibrate parameters $\{\alpha, \bar{\theta}, \bar{\psi}\}$. Then, we use the Bayesian method to estimate parameters $\left\{\gamma_{h}, \gamma_{e}, \Omega, g_{\gamma}, \bar{\lambda}_{q}\right\}$ and shock parameters. Last, we use the steady-state values $\left\{R, \frac{\tilde{K}}{\tilde{Y}}, \frac{\tilde{I}}{\tilde{K}}, \frac{\tilde{q}_{l} L_{e}}{\tilde{Y}}, \frac{\tilde{q}_{l} L_{h}}{\tilde{Y}}\right\}$ to pin down the remaining parameters $\left\{\beta, \bar{\lambda}_{a}, \bar{\varphi}, \phi, \delta\right\}$.

In Liu et al. (2013), the Frisch elasticity of labor supply is infinite, to see what will happen by only introducing a finite Frisch elasticity of labor supply, we take the value of $\sigma$ to be unity and follow the above procedures to estimate the corresponding parameters. Then, to measure the effect of consumption-labor complementarities on the amplification mechanism of the credit constraint triggered by a housing demand shock, we also estimate the parameter values which correspond to the case in which $\sigma=2 .^{6}$

Table 1 reports the prior distributions and the posterior modes of structural parameters, and Table 2 reports the prior distributions and the posterior modes of shock parameters. It is noticeable that, except for $\rho_{z}$ and $\sigma_{a}$, in general, the estimated parameters in our model suggest that those estimated in Liu et al. (2013) are quite robust.

\footnotetext{
${ }^{5}$ As in Liu et al. (2013), we use the same optimization routine which is based on Sims et al. (2008), and coded by Waggoner and Zha in C/C++. Compared with other options in the optimization routine in dynare, the optimization routine used in Liu et al. (2013) is both efficient and able to find the global posterior mode. The readers can download the source code (with the main function file "dsgelinv1_estmcmc.c") from http://www.tzha.net/ articles\#CREDITCONSTRAINTS.

${ }^{6} \sigma=2$ is broadly accepted in the literature, see, among many others, Kocherlakota (1996), Lucas (2003), Schmitt-Grohe and Uribe (2007) and Liu et al. (2016).
} 


\section{Economic implications}

When we introduce a complementary relationship between consumption and labor hours into the representative household's period utility function in Liu et al. (2013). We reap two concomitant advantages. First, in our model, Frisch elasticity of labor supply is finite intrinsically. Second, the household prefers a smooth consumption profile while, in Liu et al. (2013), the household's saving behavior is not affected by the changes in the interest rate. To understand our results clearly, we first analyze the case in which Frisch elasticity of labor supply is finite but there is no consumption-labor complementarities; then we examine what will happen when there exists a complementary relationship between consumption and labor hours. $^{7}$

\subsection{Frisch elasticity of labor supply}

Note that our model is different from Liu et al. (2013), even in the case in which $\sigma=1$. When $\sigma=1$, the representative household's utility function reduces to the separable form

$$
\mathbf{E}_{0} \sum_{t=0}^{\infty} \beta^{t} A_{t}\left\{\ln \left(C_{h t}-\gamma_{h} C_{h, t-1}\right)+\varphi_{t} \ln L_{h t}+\psi_{t} \ln \left(1-N_{h t}\right)\right\} .
$$

As a comparison, in Liu et al. (2013), the representative household's utility function is

$$
\mathbf{E}_{0} \sum_{t=0}^{\infty} \beta^{t} A_{t}\left\{\ln \left(C_{h t}-\gamma_{h} C_{h, t-1}\right)+\varphi_{t} \ln L_{h t}-\psi_{t} N_{h t}\right\}
$$

In Liu et al. (2013), the period utility function is linear in leisure, thus it implies that Frisch elasticity of labor supply is infinite. Eq. (12), however, implies that Frisch elasticity of labor supply is $\frac{1-N_{h t}}{N_{h t}}$, which is finite. When $\sigma=1$, comparing with Liu et al. (2013), the representative household is less willing to work if the real wage increases. Fig. 1 shows the impulse responses of the land price and other key macroeconomic variables following a housing demand shock. When a housing demand shock occurs, as in Liu et al. (2013), the household's land demand curve moves upward and land price rises. The rise in land price raises the entrepreneur's net worth thus loosens her borrowing constraint. Accordingly, the entrepreneur's land demand curve moves upward, which triggers the competing demand for land from the two sectors. The competing demand for land drives the land price up thus expands the entrepreneur's borrowing capacity further, and produces a static financial multiplier. By now, there's no marked difference in logic between Liu et al. (2013) and our model.

However, when we consider the dynamic financial multiplier, the situation is different. In Liu et al. (2013), with more credit, the entrepreneur will invest more in the current period, thus a large stock of capital accumulates gradually. Since capital and land are complementary in the production function, a large stock of capital in the future raises the marginal product of land at that time, thus further drives the current land price up, which produces a ripple effect. In our model, when $\sigma=1$, with more credit, the entrepreneur is still willing to invest more in the current period, but her willingness to invest is limited by the household's willingness to work. As mentioned previously, in this case, Frisch elasticity of labor supply is $\frac{1-N_{h t}}{N_{h t}}$, which is far smaller than infinity as in Liu et al. (2013). Since labor hours and capital are complementary production factors, a lower labor supply will decrease the marginal product of capital. A lower marginal product of capital implies a lower shadow price of capital in consumption units, which lowers the entrepreneur's willingness to invest. As a result, in our model, the future capital stock is lower than that in Liu et al. (2013). The analysis implies that the value of the entrepreneur's collateral capital falls short of that in Liu et al. (2013), thus the entrepreneur borrows less from the household. In addition, the decline in labor supply and the capital stock tends to reduce the marginal product of land, due to the fact that capital, land, and labor hours are complementary in the production function, which depresses the current land price. Once again, the degree with which the entrepreneur's credit constraint is relaxed is lower than that in Liu et al. (2013). Thus, the dynamic process implies that the land price rises but cannot reach the level displayed by Liu et al. (2013). It is no wonder that, in Fig. 1, the responses of land price, investment, output, consumption and labor hours are all smaller than those in Liu et al. (2013). In other words, credit constraints cannot amplify a housing demand shock as greatly as described by Liu et al. (2013). In a discussion on Liu et al. (2013), Christiano also draws a similar conclusion. ${ }^{8}$

Though Fig. 1 reveals the striking contrast between impulse responses in Liu et al. (2013) and those in our model when $\sigma=1$, variance decompositions reported in Table 3(a) show that, in general, a housing demand shock, like in Liu et al. (2013), is still the main driving force to account for the fluctuations in key macroeconomic variables. Specifically, a housing demand shock can drive most of the fluctuations in land price (about 90\%). Through amplification mechanism of borrowing constraints, though greatly moderated by the household's willingness to work, a housing demand shock causes a large fraction of the fluctuations in investment (about 35-40\%). But for output and labor hours, the labor supply shock replaces the housing demand shock to be the primary force to drive their fluctuations. To be specific, the labor supply

\footnotetext{
7 Throughout the paper, LWZ denotes Liu et al. (2013) in all the tables and Fig. 1.

${ }^{8}$ The discussion is available at http://faculty.wcas.northwestern.edu/ $/$ christ/research/LiuWangZha/discussion.pdf In the discussion, Christiano sets Frisch elasticity of labor supply to be unity.
} 

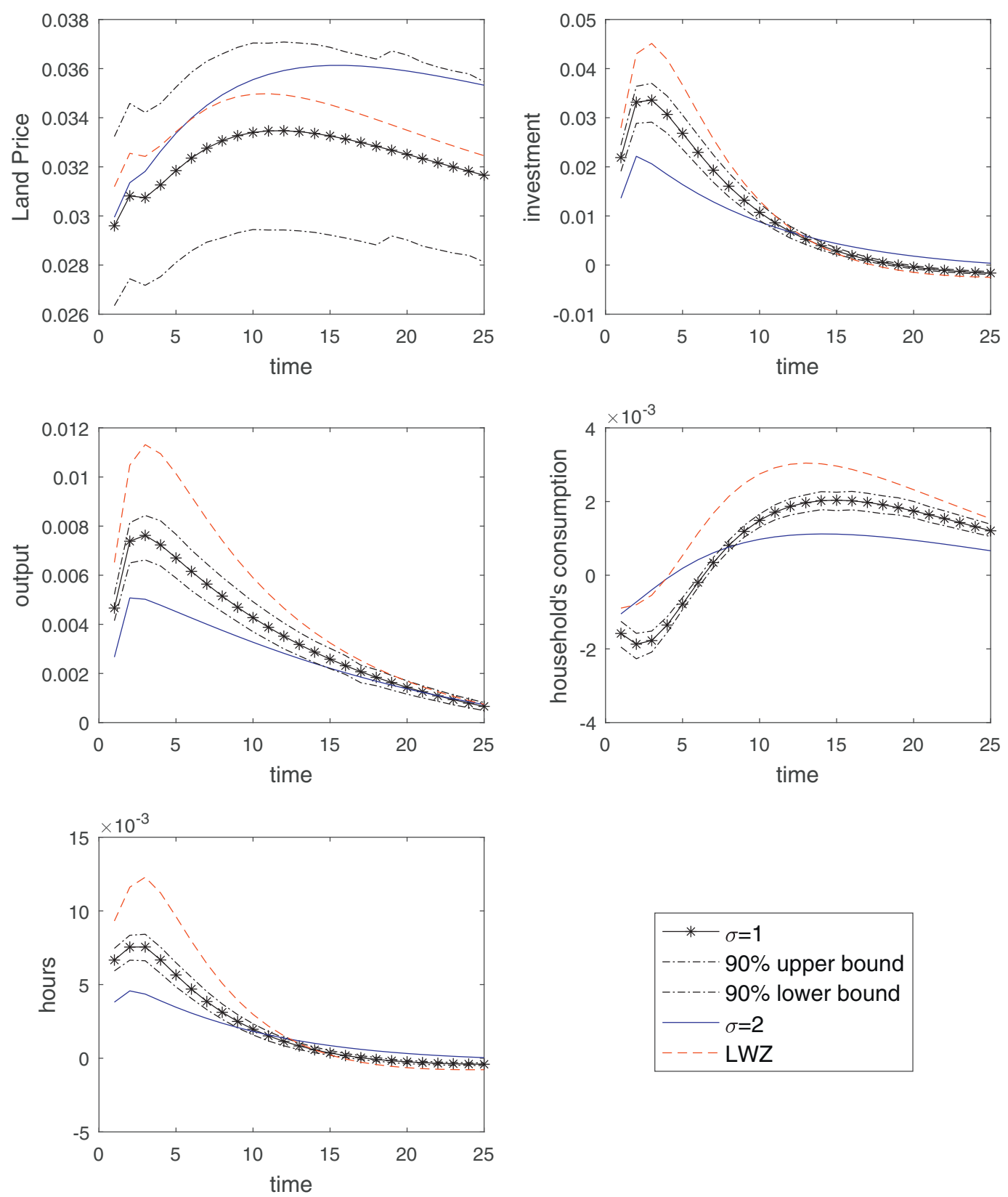

Fig. 1. Impulse responses to a positive (one standard deviation) shock to housing demand.

shock accounts for about 35-60\% of the fluctuations in output, and $40-70 \%$ of the fluctuations in labor hours. In view of our modification to Frisch elasticity of labor supply, the result is quite normal.

In fact, Liu et al. (2013) extend the benchmark model to discuss several variations in Appendix F, one of which is a finite Frisch elasticity of labor supply. They reestimate the model and find that the posterior mode estimate of the Frisch elasticity of labor supply is $\mathbf{0 . 4 7 6 2}$. However, Liu et al. (2013) do not discuss the economic implications of a finite Frisch elasticity of labor supply in detail. To check whether a finite Frisch elasticity of labor supply is favored by the data, in Table 4, we report the marginal data density (MDD, also known as marginal likelihood, the most comprehensive measure of fit) for the case in which $\sigma=1$ using three methods. After comparison, we know that, no matter which method we choose to estimate the 
Table 3(a)

Variance decompositions of aggregate quantities.

\begin{tabular}{|c|c|c|c|c|c|c|c|c|c|c|c|c|}
\hline \multirow[t]{2}{*}{ Patience } & \multicolumn{3}{|c|}{ Land price } & \multicolumn{3}{|c|}{ Investment } & \multicolumn{3}{|c|}{ Output } & \multicolumn{3}{|l|}{ Hours } \\
\hline & LWZ & $\sigma=1$ & $\sigma=2$ & LWZ & $\sigma=1$ & $\sigma=2$ & LWZ & $\sigma=1$ & $\sigma=2$ & LWZ & $\sigma=1$ & $\sigma=2$ \\
\hline $1 \mathrm{Q}$ & 4.09 & 4.19 & 8.48 & 19.37 & 15.15 & 40.73 & 12.28 & 8.87 & 16.10 & 12.46 & 10.18 & 19.90 \\
\hline $4 Q$ & 3.30 & 3.66 & 7.87 & 18.80 & 14.89 & 38.24 & 11.22 & 8.55 & 15.57 & 11.88 & 9.18 & 17.73 \\
\hline $8 Q$ & 2.91 & 3.42 & 7.62 & 17.23 & 15.56 & 39.64 & 9.68 & 8.44 & 15.71 & 10.72 & 7.83 & 15.23 \\
\hline $16 Q$ & 2.29 & 2.94 & 6.97 & 14.91 & 15.68 & 40.15 & 7.43 & 7.86 & 15.50 & 9.29 & 5.89 & 11.33 \\
\hline $24 Q$ & 1.77 & 2.44 & 6.14 & 13.56 & 15.30 & 39.36 & 5.97 & 7.07 & 14.55 & 8.68 & 4.80 & 8.86 \\
\hline \multicolumn{13}{|l|}{ Housing } \\
\hline 1Q & 89.99 & 91.15 & 80.65 & 35.46 & 34.33 & 20.41 & 27.82 & 25.34 & 10.53 & 44.87 & 29.08 & 13.03 \\
\hline $4 Q$ & 90.74 & 91.93 & 80.89 & 41.19 & 38.72 & 28.12 & 31.80 & 30.76 & 18.28 & 44.94 & 27.30 & 14.29 \\
\hline $8 Q$ & 90.28 & 91.87 & 80.17 & 38.71 & 38.29 & 27.29 & 28.32 & 29.01 & 17.01 & 42.50 & 23.21 & 12.18 \\
\hline $16 Q$ & 89.58 & 92.32 & 80.82 & 33.70 & 36.42 & 25.00 & 21.82 & 24.22 & 13.81 & 37.54 & 17.23 & 8.70 \\
\hline $24 Q$ & 89.27 & 92.90 & 81.90 & 30.67 & 35.31 & 23.49 & 17.37 & 20.30 & 11.26 & 34.75 & 14.06 & 6.71 \\
\hline \multicolumn{13}{|l|}{ Labor } \\
\hline 1Q & 2.55 & 2.72 & 5.50 & 12.06 & 17.43 & 23.86 & 21.85 & 35.48 & 48.48 & 20.20 & 40.72 & 59.95 \\
\hline $4 Q$ & 2.25 & 2.28 & 5.31 & 12.02 & 14.25 & 16.37 & 21.13 & 33.99 & 40.86 & 24.08 & 46.06 & 61.25 \\
\hline $8 Q$ & 2.41 & 2.53 & 5.79 & 12.56 & 15.49 & 17.10 & 22.22 & 39.20 & 43.41 & 29.75 & 54.19 & 67.27 \\
\hline $16 Q$ & 2.68 & 3.04 & 6.77 & 13.00 & 18.56 & 20.47 & 23.85 & 49.38 & 50.70 & 37.68 & 65.38 & 76.18 \\
\hline $24 Q$ & 2.72 & 3.36 & 7.57 & 12.63 & 20.56 & 23.62 & 23.87 & 57.22 & 57.43 & 41.45 & 71.14 & 81.27 \\
\hline \multicolumn{13}{|l|}{ Collateral } \\
\hline 1Q & 0.00 & 0.14 & 0.29 & 12.33 & 14.30 & 4.63 & 9.17 & 9.95 & 2.52 & 13.82 & 11.43 & 3.11 \\
\hline $4 Q$ & 0.11 & 0.05 & 0.07 & 16.08 & 19.49 & 11.55 & 12.12 & 15.61 & 8.85 & 13.09 & 10.37 & 4.20 \\
\hline $8 Q$ & 0.25 & 0.15 & 0.15 & 14.65 & 18.81 & 11.33 & 10.32 & 14.30 & 8.10 & 11.56 & 8.09 & 3.27 \\
\hline $16 Q$ & 0.35 & 0.29 & 0.36 & 12.42 & 17.38 & 10.31 & 7.38 & 11.20 & 6.33 & 9.99 & 5.89 & 2.11 \\
\hline $24 Q$ & 0.29 & 0.26 & 0.44 & 11.51 & 17.04 & 9.65 & 5.74 & 9.13 & 5.07 & 9.83 & 5.31 & 1.73 \\
\hline
\end{tabular}

MDD, its value in the case in which $\sigma=1$ is always higher than its counterpart in Liu et al. (2013). ${ }^{9}$ Therefore, when we introduce a finite Frisch elasticity of labor supply, the quality of the fit of the model to the data is higher. ${ }^{10}$

\subsection{Consumption-labor complementarities}

In general, when $\sigma$ is greater than unity, the elasticity of intertemporal substitution in consumption is lower than unity. The substitution effect of an increase in the interest rate is lower than the income effect, which implies that the household prefers a smooth consumption profile. In addition, the nonseparable preferences between consumption and leisure in Eq. (1) imply that the marginal utility of consumption of goods is decreasing in consumption of leisure. In other words, there is a substitute relationship between consumption and leisure. Equivalently, consumption and labor hours are complementary. After a simple calculation, we know that Frisch elasticity of labor supply is $\frac{\left(1-N_{h t}\right) \sigma}{N_{h t}\left(\sigma-\psi_{t}(1-\sigma)\right)}$, which is lower than $\frac{1-N_{h t}}{N_{h t}}$ for our estimated parameters.

We have already shown that a finite Frisch elasticity of labor supply by itself can reduce the amplification effect of the credit constraint mechanism triggered by a housing demand shock on key macroeconomic variables. In the following, we will show that, with a finite Frisch elasticity of labor supply being present, the household's stronger motive to have a smooth consumption profile and the complementary relationship between consumption and labor hours can reduce the amplification effect further.

When a housing demand shock occurs, similarly, the household's increased demand for land will drive land price up. A higher land price expands the entrepreneur's net worth and thus loosens her borrowing constraint. However, unlike Liu et al. (2013) and the case in which $\sigma=1$, when $\sigma$ is greater than unity, the household is more willing to have a smooth consumption profile, and less willing to lend the loanable bond to the entrepreneur. The impulse response of household's consumption in Fig. 1 confirms the point, the household's consumption decreases less when the housing demand shock hits the economy and exhibits a smoother pattern afterwards in the case in which $\sigma=2$ than the case in which $\sigma=1$. The

\footnotetext{
${ }^{9}$ In Liu et al. (2013), the MDD for the benchmark model is 2343.9 .

${ }^{10}$ When estimating a model with the financial frictions as in Liu et al. (2013) and labor-market search frictions to account for the dynamic relationship between the land price and the unemployment rate in the U.S. data, Liu et al. (2016) find that the observed comovement between business investment and land price forces the estimated curvature parameter of the disutility function of labor hours to be almost zero, which means that the Frisch elasticity of labor supply is near infinite, if the curvature parameter of the disutility function of labor hours measures the Frisch elasticity of labor supply as in the literature without labor-market search frictions. However, as emphasized in Liu et al. (2016), there is in general no direct mapping from the curvature parameter of the disutility function of labor hours to the intertemporal labor supply elasticity.
} 
same reasoning also applies to the consumption comparison between the case in which $\sigma=2$ and Liu et al. (2013). ${ }^{11}$ Thus, in the case in which $\sigma=2$, the entrepreneur's borrowing capacity is weakened by the household's willingness to lend. As a result, the entrepreneur's land demand curve does not move as high as that in both Liu et al. (2013) and the case in which $\sigma=1$. In other words, the competing demand for land from the entrepreneur is depressed. It means that the static financial multiplier from the competing demand for land is not as large as that in Liu et al. (2013) and when $\sigma=1$.

Nevertheless, the initial rise in land price causes the entrepreneur to borrow the loanable bond from the household, which decreases the household's consumption when the housing demand shock hits the economy. Since consumption goods and labor are complements, compared with Liu et al. (2013), the initial decline in household's consumption induces the household to decrease the labor supply. In addition, a smaller Frisch elasticity of labor supply than that in Liu et al. (2013) also lowers the household's willingness to supply labor. Thus, when the housing demand shock hits the economy, the household's willingness to supply labor is the lowest in the case in which $\sigma=2$. Naturally, among three impulse response curves of household's labor hours in Fig. 1, the one corresponding to $\sigma=2$ is at the bottom, and the one corresponding to $\sigma=1$ is in the middle, by comparison, the one corresponding to Liu et al. (2013) is at the top.

Thus, when $\sigma=2$, the previous analysis shows that the business investment in the current period is lower than that in both Liu et al. (2013) and the case in which $\sigma=1$, due to the household's stronger motive to have a smooth consumption profile. In addition, both a finite Frisch elasticity of labor supply and the complementary relationship between consumption and labor hours reduce the household's willingness to supply labor. A lower labor supply then decreases the marginal product of capital, due to the fact that labor hours and capital are complementary production factors, which lowers the shadow price of capital in consumption units. Thus, the business investment and the future capital stock are lower than that in Liu et al. (2013) and the case in which $\sigma=1$. The impulse response of investment in Fig. 1 confirms our analysis. Since the value of the entrepreneur's collateral capital falls, the entrepreneur can borrow less from the household. In addition, due to the complementary relationship among three production factors in the production function, with the future capital stock and the labor hours being lower, the future marginal product of land will also be lower, which reduces the current land price and the value of the entrepreneur's collateral land. The entrepreneur's borrowing capacity is reduced further. Thus, our analysis indicates that the dynamic financial multiplier and the resultant ripple effect are smaller than those in Liu et al. (2013) and the case in which $\sigma=1$. Accordingly, the amplification effect of the credit constraint mechanism triggered by a housing demand shock on output is the smallest among the three cases in Fig. 1.

By now, the analyses of the static and dynamic financial multipliers lead one to conclude that the land price is the lowest in the case in which $\sigma=2$. After inspecting Fig. 1, careful readers may ask why land price in the case in which $\sigma=2$ is higher than that in the case in which $\sigma=1$ and it is even higher than that corresponding to Liu et al. (2013) after about 6 periods. $^{12}$ The reason lies in our estimation results. In Section 3, we estimate that the standard deviation of the housing demand shock is 0.0522 . As a comparison, its counterparts in Liu et al. (2013) and the case in which $\sigma=1$ are 0.0462 and 0.0459 respectively. Thus, the housing demand shock in the case in which $\sigma=2$ is the strongest among three cases. As emphasized in Liu et al. (2013), a housing demand shock can drive land-price fluctuations. The relationship between the housing demand shock and the land price is described by

$$
q_{l t}=\beta \mathbf{E}_{t} \frac{\mu_{h t+1}}{\mu_{h t}} q_{l t+1}+\frac{A_{t} \varphi_{t}}{\mu_{h t} L_{h t}},
$$

in which $\mu_{h t}$ is the Lagrangian multiplier of the household's budget constraint (2), and represents the marginal utility of one unit of income. From Eq. (14), we know clearly that the marginal rate of substitution between consumption and land can directly influence the land price. With the housing demand shock being stronger, the marginal rate of substitution between consumption and land becomes higher. The household's land demand curve moves more upward and the land price is higher. Thus the stronger housing demand shock in the case in which $\sigma=2$ explains the impulse responses of the land price in Fig. 1.

As emphasized previously, our estimation generates a slightly higher land price in Fig. 1 when $\sigma=2$. By chance, it provides a natural experiment to verify our conclusion that the amplification effect of the credit constraint mechanism triggered by a housing demand shock is far smaller than that stated by Liu et al. (2013). If the land price in the case in which $\sigma=2$ were lower, the degrees to which investment, output and labor hours rise should be further depressed in Fig. 1 . From Eq. (7), we know that the amount of the debt that the entrepreneur can borrow from the household depends on the value of land and capital. A slightly higher land price in the case in which $\sigma=2$ can loosen the entrepreneur's borrowing constraint and expand her borrowing capacity. However, the household's stronger motive to have a smooth consumption profile directly limits the entrepreneur's borrowing capacity. Moreover, as analyzed previously, a finite Frisch elasticity of labor supply and the complementary relationship between consumption and labor decrease the shadow price of capital in

\footnotetext{
11 However, as analyzed in the following, in Liu et al. (2013), the fact that the amplification effect of the credit constraint mechanism triggered by a housing demand shock on output is greater than that in the case in which $\sigma=2$ implies that the household in Liu et al. (2013) is also wealthier. Thus, through this channel, the household's consumption decreases less in Liu et al. (2013) than that in the case in which $\sigma=2$. Overall, the impulse response of household's consumption displays no marked difference between Liu et al. (2013) and the case in which $\sigma=2$ in the first few quarters after the housing demand shock hits the economy.

12 In spite of this, the impulse response curve in the case in which $\sigma=2$ is still within the $90 \%$ probability bands, which implies that there is no significant difference between land prices.
} 
Table 3(b)

Variance decompositions of aggregate quantities.

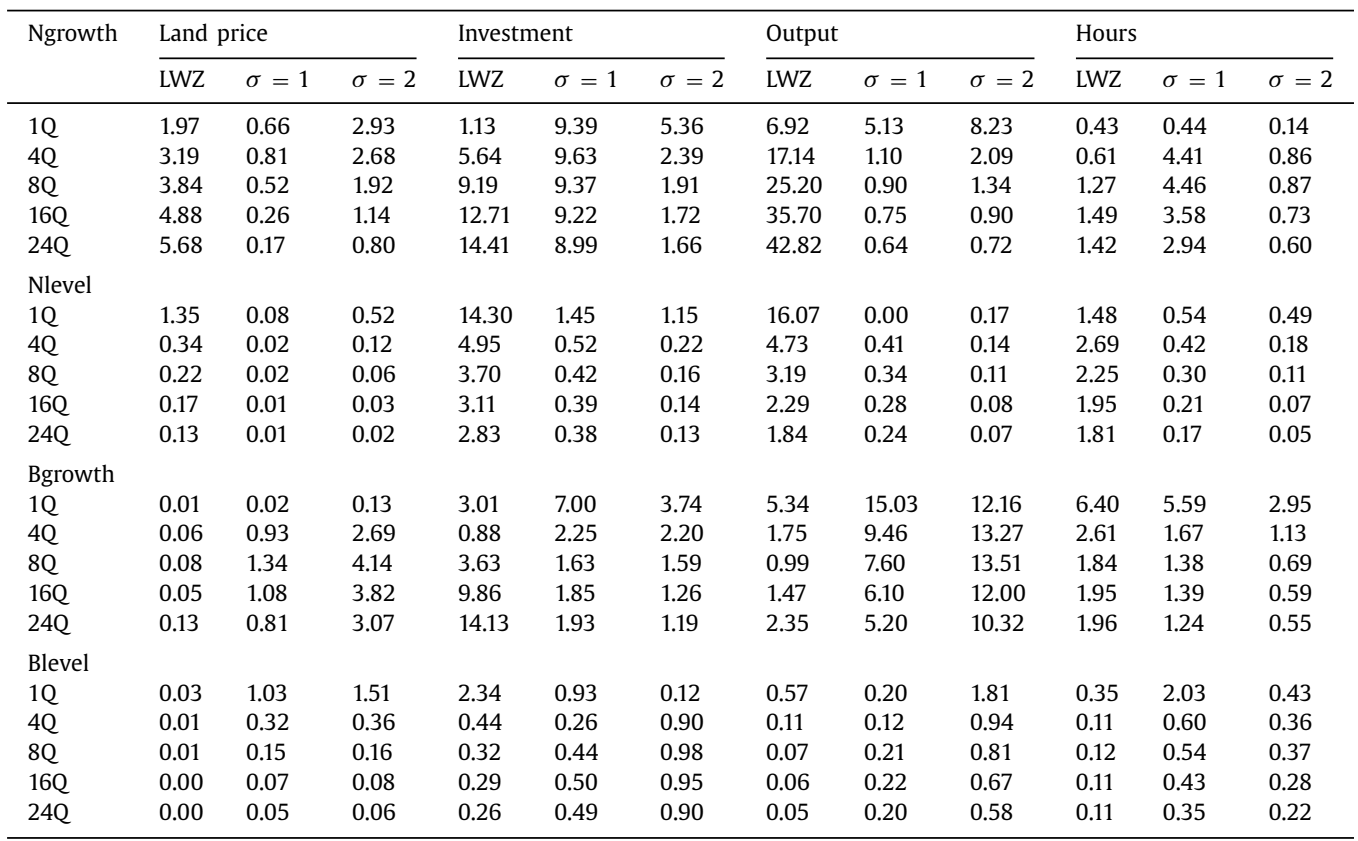

Table 4

Measures of model fit for different $\sigma$ values.

\begin{tabular}{llll}
\hline Fit measure (log value) & $\sigma=1$ & $\sigma=2$ & Estimated $\sigma$ \\
\hline MDD (SWZ) & 2353.6 & 2343.3 & 2356.8 \\
MDD (Mueller) & 2353.6 & 2342.1 & 2356.9 \\
MDD (Bridge) & 2353.5 & 2342.1 & 2356.9 \\
\hline
\end{tabular}

consumption units and the future capital stock. Thus, the value of the entrepreneur's collateral capital falls, which indirectly reduces the amount of the debt that the entrepreneur can borrow from the household. As a matter of fact, in our model, the force that tends to reduce the amount of the debt that the entrepreneur can borrow from the household directly and indirectly is so strong that it exceeds the force that expands the entrepreneur's borrowing capacity, due to a slightly higher land price. As a result, the amount of the debt that the entrepreneur borrows from the household is the least in the case in which $\sigma=2$. A similar analysis shows that the amount of the debt that the entrepreneur borrows from the household in the case in which $\sigma=1$ is less than that in Liu et al. (2013).

Our revision of the household's utility function in Liu et al. (2013) also changes the relative importance of the shocks in driving the fluctuations in the land price and other key macroeconomic variables. Variance decompositions reported in Table 3(b) reveal that the housing demand shock cannot play the most important role in driving the fluctuations in the major macroeconomic variables in the case in which $\sigma=2$. Specifically, a housing demand shock is still the most important force to drive the fluctuations in land price (about $80 \%$ ), but a labor supply shock ranks the first to drive the fluctuations in output (about 40-55\%) and labor hours (about 60-80\%). In addition, a patience shock, by comparison, is the most important to drive the fluctuations in investment (about 40\%).

In a nutshell, the striking amplification effects of a housing demand shock through the credit constraint mechanism on key macroeconomic variables in Liu et al. (2013) originate from the fact that they have used special assumptions of the household's period utility function. When we revise the household's period utility function to allow consumption and labor hours to be complementary, the original propagation mechanism still persists, but the amplification of the credit constraint mechanism triggered by a housing demand shock is far smaller than that claimed by Liu et al. (2013). The revision of the household's period utility function in Liu et al. (2013) also changes the relative importance of the shocks.

\subsection{A discussion of $\sigma$ value}

As discussed by Christiano, Liu et al. (2013) is serious about both econometrics and economics and sets a high standard for empirical work. It makes one want to know whether our introduction of a complementary relationship between consumption and labor hours is preferred by the data. In this subsection, we briefly discuss the fit to data by reporting the MDD in the cases in which $\sigma=2$ and $\sigma=1$, and comparing each MDD to its counterpart in Liu et al. (2013). The results are reported in Table 4. 
Table 5(a)

Variance decomposition for correlated patience shock and housing demand shock.

\begin{tabular}{|c|c|c|c|c|c|c|c|c|c|c|c|c|c|}
\hline \multirow{2}{*}{\multicolumn{2}{|c|}{$\frac{\text { Variable }}{\text { Correlation }}$}} & \multicolumn{6}{|c|}{ Land price } & \multicolumn{6}{|c|}{ Investment } \\
\hline & & 0.25 & 0.15 & 0.05 & -0.05 & -0.15 & -0.25 & 0.25 & 0.15 & 0.05 & -0.05 & -0.15 & -0.25 \\
\hline \multirow{4}{*}{ Patience } & $1 \mathrm{Q}$ & 23.52 & 16.82 & 11.01 & 6.23 & 2.66 & 0.51 & 49.32 & 45.87 & 42.44 & 39.03 & 35.62 & 32.24 \\
\hline & $8 Q$ & 22.24 & 15.67 & 10.04 & 5.48 & 2.17 & 0.31 & 49.60 & 45.60 & 41.62 & 37.66 & 33.74 & 29.85 \\
\hline & $24 Q$ & 20.14 & 13.74 & 8.38 & 4.21 & 1.40 & 0.15 & 48.52 & 44.83 & 41.18 & 37.56 & 33.98 & 30.44 \\
\hline & $1 \mathrm{Q}$ & 66.87 & 73.10 & 78.40 & 82.61 & 85.55 & 86.98 & 16.72 & 18.36 & 19.79 & 20.96 & 21.84 & 22.36 \\
\hline \multirow[t]{3}{*}{ Housing } & $8 Q$ & 66.90 & 72.96 & 78.04 & 82.00 & 84.64 & 85.75 & 21.98 & 24.29 & 26.36 & 28.14 & 29.59 & 30.60 \\
\hline & $24 Q$ & 69.10 & 75.05 & 79.92 & 83.56 & 85.79 & 86.40 & 19.16 & 21.07 & 22.75 & 24.15 & 25.22 & 25.89 \\
\hline & $1 \mathrm{Q}$ & 4.86 & 5.10 & 5.36 & 5.65 & 5.97 & 6.32 & 20.85 & 21.96 & 23.19 & 24.57 & 26.12 & 27.88 \\
\hline \multirow[t]{2}{*}{ Labor } & $8 Q$ & 5.15 & 5.39 & 5.65 & 5.94 & 6.25 & 6.61 & 14.69 & 15.57 & 16.56 & 17.68 & 18.97 & 20.45 \\
\hline & $24 Q$ & 6.82 & 7.10 & 7.41 & 7.75 & 8.12 & 8.52 & 20.55 & 21.67 & 22.93 & 24.34 & 25.94 & 27.76 \\
\hline \multicolumn{2}{|l|}{ Variable } & \multicolumn{6}{|c|}{ Output } & \multicolumn{6}{|l|}{ Hours } \\
\hline \multicolumn{2}{|c|}{ Correlation } & 0.25 & 0.15 & 0.05 & -0.05 & -0.15 & -0.25 & 0.25 & 0.15 & 0.05 & -0.05 & -0.15 & -0.25 \\
\hline \multirow{4}{*}{ Patience } & $1 \mathrm{Q}$ & 21.84 & 19.48 & 17.20 & 15.02 & 12.93 & 10.96 & 26.62 & 23.87 & 21.20 & 18.63 & 16.15 & 13.78 \\
\hline & $8 Q$ & 23.04 & 20.00 & 17.11 & 14.36 & 11.79 & 9.40 & 21.34 & 18.82 & 16.40 & 14.09 & 11.91 & 9.86 \\
\hline & $24 Q$ & 20.20 & 17.86 & 15.62 & 13.50 & 11.51 & 9.65 & 12.63 & 11.05 & 9.57 & 8.17 & 6.86 & 5.66 \\
\hline & $1 \mathrm{Q}$ & 9.27 & 9.91 & 10.37 & 10.65 & 10.72 & 10.56 & 11.30 & 12.15 & 12.79 & 13.21 & 13.38 & 13.28 \\
\hline \multirow[t]{3}{*}{ Housing } & $8 Q$ & 14.75 & 15.85 & 16.69 & 17.25 & 17.48 & 17.36 & 10.69 & 11.44 & 11.99 & 12.32 & 12.41 & 12.25 \\
\hline & $24 Q$ & 9.94 & 10.61 & 11.10 & 11.38 & 11.44 & 11.26 & 6.05 & 6.41 & 6.64 & 6.74 & 6.71 & 6.54 \\
\hline & $1 \mathrm{Q}$ & 45.52 & 46.66 & 47.86 & 49.12 & 50.45 & 51.86 & 55.48 & 57.19 & 59.00 & 60.93 & 62.99 & 65.20 \\
\hline \multirow[t]{2}{*}{ Labor } & $8 Q$ & 40.15 & 41.39 & 42.72 & 44.13 & 45.64 & 47.26 & 62.99 & 64.64 & 66.37 & 68.20 & 70.14 & 72.18 \\
\hline & $24 Q$ & 54.07 & 55.36 & 56.72 & 58.15 & 59.65 & 61.22 & 78.27 & 79.45 & 80.66 & 81.90 & 83.19 & 84.52 \\
\hline
\end{tabular}

Like Liu et al. (2016), we estimate the MDD using three methods with different theoretical foundations. In Table 4, SWZ denotes the method given by Sims et al. (2008), Mueller is the Mueller method which is described in detail by Liu et al. (2011), and Bridge represents the bridge-sampling method which is developed by Meng and Wong (1996). An inspection of Table 4 reveals that the data favors the case in which $\sigma=1$ rather than $\sigma=2$. However, no matter which method we choose to estimate the MDD, its value in the case in which $\sigma=2$ is just slightly lower than its counterpart in Liu et al. (2013). Thus, according to Liu et al. (2013)'s standard, the quality of the fit to the date for the case in which $\sigma=2$ is nearly identical to that in Liu et al. (2013). In order to better fit the data, we also estimate $\sigma$ using the Bayesian method. We set the prior distribution of $\sigma$ to be Gamma $(7.3850,5.2994)$ with $90 \%$ probability interval being $[0.67,2.33]$, thus, it can covers a wide range of possible values, including that estimated by Smets and Wouters (2007). The estimated value of $\sigma$ is 1.2341 , which means that the data supports our assumption that there is a complementary relationship between consumption and labor hours. In Table 4, we also report the MDD of the estimated $\sigma$ and find that the estimates of the MDD from the three methods all indicate that the data favors the estimated $\sigma$. Therefore, though there is a difference in quantity, our conclusion that the amplification effect of the credit constraint mechanism triggered by a housing demand shock on the key macroeconomic variables is greatly muted, after we revise the household's period utility function in Liu et al. (2013) to allow for a complementary relationship between consumption and labor, still holds, and it is supported by the data.

\subsection{Robustness to correlated shocks}

Variance decompositions show that, except for land price, the housing demand shock cannot play the most important role in driving the fluctuations in other major macroeconomic variables in the case in which $\sigma=2$. Our conclusion is based on the assumption that the shocks are uncorrelated. However, it is possible that some shocks are correlated. Are variance decomposition results robust to the correlations between the shocks. In the following, we show that our variance decomposition results are robust to the correlations between the shocks. ${ }^{13}$ The results are reported in Table 5(a). To save the space, we only report the results for the impact period (1Q), two years (8Q), and six years (24Q) after the initial shock. For the same reason, we omit variance decompositions for other 5 shocks and only focus on the patience shock, the housing demand shock, and the labor supply shock, which are found to be important to drive the fluctuations in key macroeconomic variables in our previous analysis. In addition, the correlation coefficient is assumed to be $-0.05,-0.15,-0.25,0.05,0.15$, 0.25 respectively.

Table 5(a) reports the variance decompositions for the land price and other key macroeconomic variables, when the patience shock $A_{t}$ is correlated to the housing demand shock $\varphi_{t}$, and Table $5(\mathrm{~b})$ reports the variance decompositions for key macroeconomic variables, when the housing demand shock $\varphi_{t}$ is correlated to the labor supply shock $\psi_{t}$. We find that our variance decompositions are quite robust to the correlated $A_{t}$ and $\varphi_{t}$, and the correlated $\varphi_{t}$ and $\psi_{t}$. However, when

\footnotetext{
${ }^{13}$ Note that, in the following, we only focus on the case in which $\sigma=2$, and our variance decompositions use the same estimated parameter values reported in Tables 1 and 2.
} 
Table 5(b)

Variance decompositions for correlated housing demand shock and labor supply shock.

\begin{tabular}{|c|c|c|c|c|c|c|c|c|c|c|c|c|c|}
\hline \multirow{2}{*}{\multicolumn{2}{|c|}{$\frac{\text { Variable }}{\text { Correlation }}$}} & \multicolumn{6}{|c|}{ Land price } & \multicolumn{6}{|c|}{ Investment } \\
\hline & & 0.25 & 0.15 & 0.05 & -0.05 & -0.15 & -0.25 & 0.25 & 0.15 & 0.05 & -0.05 & -0.15 & -0.25 \\
\hline & $1 \mathrm{Q}$ & 9.48 & 9.05 & 8.66 & 8.31 & 7.98 & 7.67 & 45.79 & 43.62 & 41.65 & 39.85 & 38.20 & 36.69 \\
\hline \multirow[t]{3}{*}{ Patience } & $8 Q$ & 8.54 & 8.14 & 7.79 & 7.46 & 7.16 & 6.88 & 44.38 & 42.35 & 40.50 & 38.81 & 37.25 & 35.81 \\
\hline & $24 Q$ & 7.01 & 6.63 & 6.29 & 5.99 & 5.71 & 5.46 & 44.01 & 42.03 & 40.21 & 38.55 & 37.02 & 35.60 \\
\hline & $1 \mathrm{Q}$ & 78.76 & 79.48 & 80.25 & 81.06 & 81.92 & 82.80 & 12.22 & 15.34 & 18.68 & 22.19 & 25.86 & 29.66 \\
\hline \multirow[t]{3}{*}{ Housing } & $8 Q$ & 78.18 & 78.94 & 79.75 & 80.60 & 81.50 & 82.42 & 19.79 & 22.72 & 25.75 & 28.85 & 32.03 & 35.27 \\
\hline & $24 Q$ & 79.88 & 80.63 & 81.46 & 82.36 & 83.31 & 84.32 & 6.10 & 18.88 & 21.90 & 25.13 & 28.55 & 32.13 \\
\hline & 1Q & 5.76 & 5.74 & 5.60 & 5.37 & 5.05 & 4.66 & 25.14 & 24.98 & 24.34 & 23.29 & 21.88 & 20.15 \\
\hline \multirow[t]{2}{*}{ Labor } & $8 Q$ & 6.08 & 6.05 & 5.90 & 5.65 & 5.32 & 4.90 & 17.95 & 17.86 & 17.43 & 16.70 & 15.71 & 14.49 \\
\hline & $24 Q$ & 8.11 & 8.00 & 7.75 & 7.37 & 6.89 & 6.32 & 24.75 & 24.65 & 24.06 & 23.07 & 21.71 & 20.02 \\
\hline \multicolumn{2}{|l|}{ Variable } & \multicolumn{6}{|c|}{ Output } & \multicolumn{6}{|l|}{ Hours } \\
\hline \multicolumn{2}{|c|}{ Correlation } & 0.25 & 0.15 & 0.05 & -0.05 & -0.15 & -0.25 & 0.25 & 0.15 & 0.05 & -0.05 & -0.15 & -0.25 \\
\hline \multirow{4}{*}{ Patience } & $1 \mathrm{Q}$ & 18.15 & 17.27 & 16.47 & 15.74 & 15.07 & 14.46 & 23.14 & 21.72 & 20.47 & 19.36 & 18.36 & 17.46 \\
\hline & $8 Q$ & 18.16 & 17.10 & 16.15 & 15.30 & 14.54 & 13.85 & 17.73 & 16.64 & 15.67 & 14.81 & 14.04 & 13.35 \\
\hline & $24 Q$ & 16.45 & 15.63 & 14.89 & 14.22 & 13.61 & 13.04 & 9.78 & 9.39 & 9.03 & 8.69 & 8.38 & 8.09 \\
\hline & $1 \mathrm{Q}$ & 2.55 & 5.20 & 8.59 & 12.63 & 17.24 & 22.34 & 3.26 & 6.54 & 10.68 & 15.54 & 21.00 & 26.97 \\
\hline \multirow[t]{3}{*}{ Housing } & $8 Q$ & 7.22 & 10.77 & 14.82 & 19.29 & 24.12 & 29.25 & 2.67 & 5.72 & 9.81 & 14.75 & 20.42 & 26.71 \\
\hline & $24 Q$ & 3.74 & 6.05 & 9.31 & 13.41 & 18.22 & 23.66 & 2.55 & 3.02 & 5.11 & 8.64 & 13.45 & 19.42 \\
\hline & $1 \mathrm{Q}$ & 51.24 & 50.84 & 49.48 & 47.29 & 44.38 & 40.84 & 65.33 & 63.96 & 61.52 & 58.17 & 54.07 & 49.31 \\
\hline \multirow[t]{2}{*}{ Labor } & $8 Q$ & 47.04 & 46.17 & 44.50 & 42.17 & 39.26 & 35.87 & 73.41 & 71.83 & 69.05 & 65.27 & 60.63 & 55.28 \\
\hline & $24 Q$ & 60.86 & 60.31 & 58.64 & 55.99 & 52.50 & 48.27 & 84.17 & 84.23 & 82.64 & 79.56 & 75.17 & 69.60 \\
\hline
\end{tabular}

the correlated shocks are more negatively correlated, the housing demand shock also becomes important to account for the fluctuations in investment.

\section{Conclusion}

In an influential paper, Liu et al. (2013) argue that a housing demand shock triggers the propagation and amplification mechanism through the borrowing constraint in the spirit of Kiyotaki and Moore (1997), and the fluctuations in the land price and the key macroeconomic variables generated by the model fit the data well. However, in their model, Frisch elasticity of labor supply is infinite, which is not supported by both macroeconomic and microeconomic estimates. In addition, a large body of literature on business cycles theory demonstrates that the complementarity between consumption and labor hours has important implications for business cycles while Liu et al. (2013) assume that there is no such relationship between consumption and labor hours.

In this paper, we introduce a complementary relationship between consumption and labor hours by revising the household's period utility function in Liu et al. (2013). Our revision concomitantly allows for a finite Frisch elasticity of labor supply and a stronger consumption smoothing motive. We find that, in general, the estimation of Liu et al. (2013) is quite robust. In addition, the propagation mechanism of the credit constraint triggered by a housing demand shock still persists. However, the amplification effect of the credit constraint triggered by the housing demand shock on key macroeconomic variables is greatly muted. We also find that, except for land price fluctuations, the housing demand shock cannot act as the primary force to drive the fluctuations in other macroeconomic variables. The estimation of the coefficient of relative risk aversion shows that the assumption of a complementary relationship between consumption and labor hours is consistent with the data, and the estimates of the MDD from various methods all indicate that our model fits the data well.

\section{Acknowledgments}

We are grateful to the editor, James Bullard, and an anonymous referee for the insightful comments and suggestions. We also appreciate comments from Jianjun Miao, Pengfei Wang, Kecheng Zhou, Meixin Guo, Ronald Carpio, Liyuan Wu, Feng Shi, Dongling Su, and seminar participants of Macro Group at GSM. We especially thank Tao Zha for teaching us his estimation method and $\mathrm{C} / \mathrm{C}++$ code.

\section{References}

Backus, D.K., Kehoe, P.J., Kydland, F.E., 1992. International real business cycles. J. Polit. Econ. 100 (4), $745-775$.

Becker, G.S., 1965. A theory of the allocation of time. Econ. J. 75 (299), 493-517.

Bernanke, B.S., Gertler, M., S., G., 1999. The financial accelerator in a quantitative business cycle framework. In: Taylor, J.b., Woodford, M. (Eds.), Handbook of Macroeconomics, vol. 1. Elsevier, pp. 1341-1393. (Chapter 21).

Cao, D., Nie, G.Y., 2017. Amplification and asymmetric effects without collateral constraints. Am. Econ. J. Macroecon 9 (3), $222-266$.

Chari, V.V., Christiano, L.J., Kehoe, P.J., 1994. Optimal fiscal policy in a business cycle model. J. Polit. Econ. 102 (4), 617-652. 
Chari, V.V., Kehoe, P.J., McGrattan, E.L., 2000. Sticky price models of the business cycle: can the contract multiplier solve the persistence problem? Econometrica 68 (5), 1151-1179.

Chetty, R., Guren, A., Manoli, D., Weber, A., 2012. Does indivisible labor explain the difference between micro and macro elasticities? A meta-analysis of extensive margin elasticities. NBER Macroecon. Ann. 27, 1-56.

Cordoba, J.C., Ripoll, M., 2004. Credit cycles redux. Inter. Econ. Rev. 45 (4), 1011-1046.

Devereux, M.B., Shi, K., Xu, J.Y., 2007. Global monetary policy under a dollar standard. J. Int. Econ. 71, $113-132$.

Dmitriev, M., Hoddenbagh, J., 2017. The financial accelerator and the optimal state-dependent contract. Rev. Econ. Dyn. 24, 43-65.

Favilukis, J., Ludvigson, S.C., Van Nieuwerburgh, S., 2017. The macroeconomic effects of housing wealth, housing finance, and limited risk-sharing in general equilibrium. J. Polit. Econ 125 (1), 140-223.

Greenwood, J., Hercowitz, Z., Huffman, G.W., 1988. Investment, capacity utilization, and the real business cycle. Am. Econ. Rev. 78 (3), $402-417$.

Hansen, G.D., 1985. Indivisible labor and the business cycle. J. Monet. Econ. 16, 309-337.

lacoviello, M., 2005. House prices, borrowing constraints, and monetary policy in the business cycle. Am. Econ. Rev. 95, $739-764$.

Iacoviello, M., Neri, S., 2010. Housing market spillovers: evidence form an estimated DSGE model. Am. Econ. J. Macroecon. 2, $125-164$.

Jermann, U., Quadrini, V., 2012. Macroeconomic effects of financial shocks. Am. Econ. Rev. 102, 238-271.

Kiyotaki, N., Moore, J., 1997. Credit cycles. J. Polit. Econ. 105 (2), 211-248.

Kocherlakota, N., 1996. The equity premium: it's still a puzzle. J. Econ. Lit. 34, 42-71.

Kocherlakota, N., 2000. Creating business cycles through credit constraints. Fed. Reserve Bank Minneap. Q. Rev. 24 (3), 2-10.

Kydland, F.E., Prescott, E.C., 1982. Time to build and aggregate fluctuations. Econometrica 50 (6), $1345-1370$.

Liu, Z., Miao, J., Zha, T., 2016. Land prices and unemployment. J. Monet. Econ. 80, 86-105.

Liu, Z., Waggoner, D.F., Zha, T., 2011. Sources of macroeconomic fluctuations: a regime-switching DSGE approach. Quant. Econ. 2 , $251-301$.

Liu, Z., Wang, P., Zha, T., 2013. Land-price dynamics and macroeconomic fluctuations. Econometrica 81, 1147-1184.

Lucas, R.E., 2003. Macroeconomic priorities. Am. Econ. Rev. 93, 1-14.

Meng, X.L., Wong, W.H., 1996. Simulating ratios of normalising constants via a simple identity: a theoretical exploration. Stat. Sinica. 6, 831-860.

Rogerson, R., 1988. Indivisible labor, lotteries and equilibrium. J. Monet. Econ. 21, 3-16.

Schmitt-Grohe, S., Uribe, M., 2007. Optimal simple and implementable monetary and fiscal rules. J. Monet. Econ. 54, $1702-1725$.

Sims, C.A., Waggoner, D.F., Zha, T., 2008. Methods for inference in large multiple-equation Markov-switching models. J. Econ. 146, $255-274$.

Smets, F., Wouters, R., 2007. Shocks and frictions in US business cycles: a Bayesian DSGE approach. Am. Econ. Rev. 97 (3), $586-606$. 